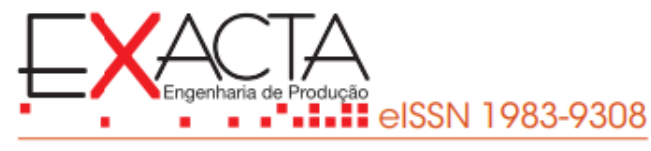

\title{
UM ESTUDO SOBRE AS CONDIÇÕES DE TRABALHO E LAYOUT INDUSTRIAL PARA A REALIZAÇÃO DE MUDANÇAS EM UMA OFICINA DE COMPONENTES FERROVIÁRIOS DA MRS LOGÍSTICA
}

\section{STUDY OF WORKING CONDITIONS AND INDUSTRIAL LAYOUT FOR CHANGES IN A RAILWAY COMPONENTS WORKSHOP MRS LOGÍSTICA}

Recebido em: 07 ago. 2020

Aprovado em: 06 fev. 2021

Versão do autor aceita publicada online: 06 fev. 2021

Publicado online: 25 jun. 2021

Como citar esse artigo - American Psychological Association (APA):

Felix, J. C., Barbosa, L. C. M., \& Valente, A. F. de. A. (2022, out./dez.). Um estudo sobre as condições de trabalho e layout industrial para a realização de mudanças em uma oficina de componentes ferroviários da mrs logística. Exacta. 20(4), 1024-1048. https://doi.org/10.5585/exactaep.2022.17873.

Submeta seu artigo para este periódico $\beta$

Dados Crossmark 


\title{
UM ESTUDO SOBRE AS CONDIÇÕES DE TRABALHO E LAYOUT INDUSTRIAL PARA A REALIZAÇÃO DE MUDANÇAS EM UMA OFICINA DE COMPONENTES FERROVIÁRIOS DA MRS LOGÍSTICA
}

\author{
STUDY OF WORKING CONDITIONS AND INDUSTRIAL LAYOUT FOR CHANGES IN A \\ RAILWAY COMPONENTS WORKSHOP MRS LOGISTICA
}

\section{Josemar Coelho Felix ${ }^{1}$ \\ iD Leandro César Mol Barbosa ${ }^{2}$ \\ Afonso Flavio De Assis Valente ${ }^{3}$}

${ }^{1}$ Mestre em Ciência da Computação Universidade Federal de Ouro Preto - UFOP. Ouro Branco - Brasil.

felix.josemar@gmail.com

${ }^{2}$ Mestre em Administração-PUC Minas Docente Titular do IFMG-Congonhas Congonhas-Brasil.

leandro.mol@ifmg.edu.br

${ }^{3}$ Especialista em Negócios - Fundação Dom Cabral Especialista Ferroviário - MRS Logística Conselheiro Lafaiete, MG - Brasil. afonso.valente@mrs.com.br

Recebido em: 07 ago. 2020

Aprovado em: 06 fev. 2021
Resumo: Este artigo apresenta uma proposta de mudanças no projeto da oficina de recuperação parcial de truques e testes de partículas magnéticas da Gerência de Manutenção-MG da MRS Logística, de forma a melhorar as condições de trabalho e garantir a segurança, eficiência produtiva, controle de custo e a satisfação do trabalhador. Esta pesquisa considerada participativa, analisou a situação do ambiente e criou ações com fundamentos bibliográficos sobre gestão de projeto, layout e unidade produtiva. A construção da caracterização do caso e compreensão dos aspectos locais, permitiu contextualizar qualitativamente a empresa, a área analisada, seus processos e as particularidades do grupo de trabalho. Isso possibilitou entender os riscos e classificá-los de acordo com cada modificação necessária. Com o término da pesquisa e realização das intervenções, verificou-se a necessidade da elaboração de um material para orientar a montagem de ambientes na empresa.

Palavras-chave: Layout. MRS Logística. Ambiente Produtivo. Ferrovia. Manutenção.

Abstract: This article presents a proposal for changes in the design of the partial recovery workshop for magnetic particles testing and tricks of the Maintenance Management-MG of MRS Logística, in order to improve working conditions and ensure safety, productive efficiency, cost control and worker satisfaction. This research, considered participatory, analyzed the situation of the environment and created actions with bibliographic foundations about project management, layout and production unit. The study made it possible to understand the aspects of the site, in order to raise and qualitatively analyze the design requirements, capable of avoiding uncertainties in maintenance management. The construction of the characterization of the case allowed to contextualize the company, the analyzed area, its processes and the particularities of the work group. This made it possible to understand the risks and classify them according to each necessary modification. With the end of the research and carrying out the interventions, there was a need to prepare a material to guide the setting up of environments in the company.

Keywords: Layout. MRS Logística. Productive environment. Railway. Maintenance. 


\section{Introdução}

Em um ambiente industrial, deve-se ter uma atenção especial sobre o layout das instalações físicas e sobre as condições de trabalho impostas por ele. Os layouts, se mal projetados, podem acarretar inúmeros problemas para o processo, como, por exemplo, ameaças à segurança do trabalhador, barreiras que prejudicam o tempo produtivo, além de riscos de impactos negativos sobre o planejamento de custos.

O processo de otimização do layout industrial engloba a combinação de diversas variáveis em um mesmo ambiente, o que gera dificuldades para realizar as mudanças de maneira precisa e eficaz. Para assegurar que o ambiente seja favorável ao trabalho, o layout adequado deve levar em conta o melhor aproveitamento do local, eliminando de espaços demasiadamente reduzidos, adequando as condições para instalações de máquinas e equipamentos e assim evitar movimentações desnecessárias e que coloquem em risco a integridade física do colaborador (Machline, 1990).

É fundamental a identificação dos fatores que tornam o ambiente de trabalho saudável, principalmente no que tange a percepção dos trabalhadores sobre o espaço, pois assim o indivíduo cria o sentimento de identidade para com a organização (Albuquerque, 2018). Compreender estes aspectos pela equipe de trabalho, leva a um direcionamento mais assertivo quanto às melhorias aplicáveis em um ambiente produtivo. Além disso, segundo Slack, Chambers e Johnston (2009) a avaliação de layouts proporciona diversas oportunidades de melhorias organizacionais. Neste contexto, a hipótese deste trabalho é que implantar melhorias no arranjo físico, no contexto organizacional, gera mudanças e adequações no ambiente de produtivo, o que impacta no aumento no desempenho operacional, fluidez no fluxo de materiais e de informações, além do comprometimento e bem-estar comum dos colaboradores que os utilizam a oficina de componentes ferroviários da MRS Logística.

Neste contexto, esta pesquisa teve como foco a implementação de modificações no arranjo físico da MRS Logística, levando em consideração toda a complexidade da organização de um ambiente fabril. Para tal, foi realizada uma pesquisa participativa, com o intuito de buscar oportunidades de melhoria em seu layout, e encontrar pontos relevantes do processo de recuperação e confiabilidade de componentes para vagões, e, consequentemente, aplicar as adaptações necessárias. A partir de informações internas da empresa, buscou-se levantar um conjunto de dados relevantes do processo, para auxiliar no desenvolvimento da pesquisa. Este levantamento se deu de forma a facilitar a compreensão e a intervenção no ambiente.

A adaptação do layout foi realizada dentro das instalações da MRS Logística; mais especificamente, em uma unidade de manutenção do KM460, localizada no município de Conselheiro Lafaiete. O objetivo geral deste trabalho, foi de realizar intervenções em um projeto de fábrica, com a finalidade de proporcionar um ambiente de trabalho mais adequado aos colaboradores que atuam 
junto à manutenção de vagões. Foi ainda utilizado o protocolo de investigação da empresa para realizar a gestão de riscos na implementação de melhorias em segurança, produtividade e custo. Buscou-se identificar e analisar requisitos considerados importantes para a MRS Logística, no tocante à adaptação do layout, para propor ações de melhoria no galpão onde é realizada a recuperação de componentes para a manutenção de vagões.

No decorrer do trabalho, foram contextualizados a MRS logística, a Gerência de Manutenção de Vagões-MG, o processo de reparação parcial de truques e teste de partículas e as condições iniciais do ambiente produtivo. As soluções abordaram seis requisitos necessários para a melhoria do ambiente produtivo, que serão detalhados posteriormente, os quais foram implantados por meio de intervenções locais. Foram discriminados os propósitos de cada oportunidade de melhoria, bem como o método de intervenção no ambiente. Todas as mudanças só foram possíveis devido ao auxílio dos colaboradores da Gerência de Manutenção de Vagões-MG (GMVMG) em todos os momentos.

\section{Revisão teórica}

O objetivo deste capítulo é fazer um levantamento teórico sobre como as características físicas do ambiente construído pode interferir no trabalho e nas pessoas que o desenvolve. Para tanto, foi realizada uma pesquisa sobre projetos, arranjos físicos e temas relacionados a gestão de projetos, para que se consiga compreender o nível de complexidade do estudo.

\subsection{Arranjo físico (layout)}

Os primeiros estudos abordando os arranjos físicos de ambientes de trabalho se desenvolveram antes da Revolução Industrial para a tratativa de problemas relacionados ao artesanato. Posteriormente à revolução, o tema foi aprofundado com o objetivo de utilizar, da melhor forma, as instalações físicas, a energia, o espaço e a matéria prima (Favaretto, Kurek, Gomes, Caibre, \& Pandolfo, 2011).

O arranjo físico, também denominado layout, pode ser conceituado como a maneira que são distribuídos os objetos de uma determinada área e as suas condições estruturais, de forma a contribuir para a melhor utilização e manuseio dos recursos disponíveis (Pache, Silva, dos Santos, Garlet, \& Godoy, 2015). Segundo Tortorella (2008), um layout bem elaborado auxilia na melhor utilização dos recursos humanos, dos equipamentos, do espaço, da energia, dos materiais, do transporte interno e, consequentemente, auxilia na eficiência operacional para a manufatura.

O estudo contínuo de melhores opções de arranjos industriais pode resultar no aumento da competitividade de uma organização. Isso se dá, em parte, pelo fato de que as pessoas passam a compreender a importância do projeto de fábrica, conseguindo aumentar a sua capacidade produtiva e aflorar alternativas mais criativas que facilitem a produção (Neumann \& Fogliatto, 2013). 
Segundo Slack, Chambers e Johnston (2009), normalmente são necessários altos investimentos para o estudo de arranjos físicos. Construir e modificar um ambiente pode ser desgastante e custoso, levando longos períodos de intervenção. Esse mesmo autor destaca cinco tipos básicos de arranjos físicos. São eles:

- Arranjo físico por produto: representa uma disposição física de equipamentos que obedece a uma sequência de montagem. As máquinas ficam posicionadas de maneira a facilitar o fluxo do processo. Esse arranjo destaca-se por proporcionar uma alta produtividade, porém a um alto custo fixo, além de apresentar pouca flexibilidade e dificuldade para montar produtos diferentes.

- Arranjo por processo (funcional): Neste ambiente, os equipamentos são agrupados de acordo com a sua função, em que o propósito de cada um é considerado geral. Apesar de ter uma produtividade baixa, ele destaca-se por ter um custo menor de construção e uma facilidade maior para mudanças. Ele é capaz de atender demandas com difícil previsibilidade e constância, mas pode exigir grande habilidade da mão de obra.

- Arranjo celular: Essa proposta de arranjo físico busca unir as vantagens do arranjo por produto e por processo, deve ser adotada quando se torna possível agrupar peças e/ou processos, para realizar um conjunto de diferentes etapas de construção do produto. 0 seu principal benefício é o aumento da flexibilidade, pois possibilita a redução do tempo de setup, do transporte de materiais e de estoques, além de facilitar a forma de trabalho. Porém, deve-se ressaltar que esse arranjo tem, como desvantagem, a pouca utilização de recursos físicos e a alta complexidade de elaboração.

- Arranjo por posição fixa: Representa uma proposta de arranjo em que o material permanece parado em uma posição e os recursos de transformação se deslocam no seu entorno. Como vantagens, pode-se destacar que, quando o produto tem grandes dimensões, realiza-se pouca movimentação. Esse tipo de arranjo facilita, também, a utilização de softwares e a terceirização de partes do processo. As desvantagens são a complexidade de gestão, as áreas grandes para alocação de material e a dificuldade para padronizar o processo.

- Arranjo físico misto: Consiste em uma proposta que combina os tipos de arranjos físicos citados anteriormente, buscando agregar suas diferentes vantagens.

A definição de um layout adequado, assim como a busca contínua pelo seu aprimoramento na indústria, vem demonstrando que, além de aspectos de processo, é imprescindível trabalhar as 
necessidades de segurança dos funcionários, dos clientes e dos produtos. A busca constante de melhorias, para aumentar ou otimizar a produção, vem tornando os arranjos mais flexíveis às mudanças de processos. Utilizar o espaço em sua plenitude pode evitar armazenamentos ineficientes e movimentos aleatórios, que trazem problemas na execução de atividades importantes dos setores de operação e de manutenção (Bem, 2013).

\subsection{Projetos e o ambiente de trabalho}

Um projeto pode ser conceituado como um esforço não repetitivo que terá, como resultado final, um produto ou serviço. É composto por metas a serem atingidas, correspondentes a resultados claros e bem definidos. Diferentemente de processos produtivos, ao se criar um projeto, deve-se estabelecer claramente o início e o fim, entendendo e controlando as suas restrições, como tempo, custo, recursos humanos e materiais (Cruz, 2013).

Para se alcançar a efetividade do projeto, a equipe tem como desafio identificar os seus requisitos, adaptando as diferentes expectativas das partes interessadas e propondo mudanças no planejamento ao longo do ciclo de vida do projeto. Para que isso seja realizado, a devida atenção deve ser despendida com relação ao balanceamento e à adequação das restrições dos recursos necessários (Méxas, 2019).

De acordo com Albuquerque (2018), deve-se oferecer constantemente segurança às atividades dentro de um ambiente, de forma que essas forneçam a proteção, a saúde e o bem-estar, o que gera um sentimento de satisfação nos indivíduos, necessário para a eficiência. Quanto a seus aspectos físicos, os projetos que buscam adequações no ambiente de trabalho devem se preocupar com as aparências superficiais dos mobiliários (Rodrigues, 2012). As cores, os formatos, a iluminação e o motivo dos itens de um projeto de fábrica devem ser claros para que o local reflita um sentimento de identidade das pessoas (Albuquerque, 2018).

Os projetos voltados a mudanças no ambiente de trabalho ganham uma relevância especial quando comparados a outros tipos de projeto. Isso acontece pois o conforto do profissional que depende de um determinado ambiente gera impacto na sua satisfação, o que pode afetar a retenção de talentos e de conhecimento na organização. Quando se realizam mudanças em um local, com a participação da mão de obra já existente na corporação, os resultados podem servir de gatilho para reavaliar os processos, as estruturas e o posicionamento dos líderes, além de auxiliar nas relações humanas dentro da organização (Cubas \& Figueiredo, 2015).

As propostas de melhoria em arranjos físicos devem levar em conta a eficiência na execução e a opinião do trabalhador que realiza a tarefa. Dessa forma, se torna suave a maneira de delegar as atividades e, consequentemente, melhora o desempenho da implementação das propostas (Masculo \& 
Vidal, 2011). A complexidade em interligar fatores e aspectos diferentes na fábrica justifica o contato com diversos profissionais especializados, o que auxilia na busca mais assertiva por mudanças e adequações no ambiente fabril (Andreto, 2005).

\subsection{Gerenciamento de escopo}

O gerenciamento adequado de um projeto pode evitar vários tipos de problemas resultantes da diversidade dos interesses dos stakeholders, que vão desde as diferenças pessoais da equipe até a falta de alinhamento dessa com os objetivos do projeto. $\mathrm{O}$ ato de gerenciar um projeto permite ter rápidas respostas às mudanças das condições do mercado, promover uma melhor adequação dos recursos, muitas vezes escassos, além de auxiliar no crescimento profissional dos envolvidos (Valle, 2015).

O escopo pode ser entendido como o conjunto de informações e elementos que compõem e representam todo o trabalho necessário para a realização do projeto. Assim, o escopo compreende a descrição do trabalho do projeto e deve estar em consonância com as informações que direcionam a realidade e as dificuldades da organização (Sotille, 2015).

Para definir o escopo do projeto, é necessário estruturar uma visão final dos resultados pretendidos. Essa visão, segundo Higsmith (2004), é o esboço que possibilita representar as principais propostas e funcionalidades do produto final a ser gerado. Segundo o PMI (2013), a construção do escopo é reconhecida como uma necessidade de controle, uma vez que é considerada como fundamental para guiar as ações do gerente de projetos.

\subsubsection{Coleta de requisitos}

Um passo importante para o entendimento e a elaboração do escopo é o levantamento dos requisitos necessários à elaboração do projeto. De acordo com o PMI (2013), os requisitos representam as necessidades das partes interessadas, que devem ser coletadas para orientar a definição do escopo e garantir a efetividade do projeto. Essa coleta deve ser realizada de maneira que os registros possuam detalhes suficientes para serem medidos e avaliados com facilidade.

Alguns requisitos permitem descrever atributos, funções e características ligadas aos objetivos finais de um empreendimento e são denominados requisitos de solução. Eles podem ser divididos em funcionais, onde descrevem como o produto deve se comportar, e não funcionais, capazes de demostrar as condições ambientais requeridas para que o produto se comporte como necessário (PMI, 2013).

Para uma melhor definição do escopo do projeto, os requisitos coletados podem ser organizados e utilizados para a elaboração da EAP (Estrutura Analítica do Projeto). A EAP pode ser 
entendida como uma estrutura organizacional disposta em forma de diagrama de níveis hierárquicos, o qual, por meio da definição de pacotes de trabalho, auxilia no levantamento das atividades necessárias para o projeto. Essas atividades devem ser planejadas e controladas pela equipe de gerenciamento (Gama, Jacubavicius, \& Formigoni, 2015).

\subsubsection{Gerenciamento de riscos}

Tão importante quanto definir os requisitos de projeto é saber qual o nível de incerteza no qual eles estão imersos. Assim, identificar os fatores de risco, com o auxílio da equipe participante do projeto, é fundamental. Quando se consegue analisar os fatores críticos de sucesso do projeto, assim como as suas restrições, torna-se possível acompanhar e garantir que qualquer alteração seja bem controlada (Baio, Falce, Rodrigues \& Ludwig, 2016).

O gerenciamento de riscos visa compreender o impacto das decisões e a busca pela tentativa de controlar as incertezas, para não depender de sorte ou azar. O controle de risco pode ser considerado como um diferencial competitivo, pois identifica fatores críticos, evita contratações de consultorias desnecessárias e minimiza impactos negativos, inclusive aqueles relacionados à integridade física das pessoas (Salles, 2006).

A análise qualitativa dos riscos é realizada através da definição de níveis de probabilidade e impacto (gravidade). O principal benefício dessa iniciativa é auxiliar a gestão em sua tomada de decisão, focando nos riscos de alta prioridade. Esses, por sua vez, são obtidos pelas reflexões sobre as atitudes da equipe envolvida (PMI, 2013).

\section{Metodologia}

A proposta de elaboração deste estudo visou analisar um ambiente de trabalho existente, a fim de estabelecer parâmetros de melhoria e realizar as devidas intervenções, através do conhecimento adquirido na revisão teórica deste estudo. Assim, o trabalho foi caracterizado como uma pesquisa aplicada, orientado para a avaliação e interferência no objeto de estudo (Gil, 2002). O estudo representa uma pesquisa indutiva, a qual pode ser entendida como uma maneira de construir abstrações a partir de dados observados no ambiente de trabalho (Zanella, 2006). Dentre essas observações, destacam-se aquelas referentes ao próprio ambiente, bem como conceitos de melhorias determinados pelas normas da empresa, utilizados para definir ações e modificar o setor de recuperação de componentes ferroviários.

Quanto à abordagem utilizada, o trabalho pode ser considerado como qualitativo, pois mostra como é a realidade subjetiva do ambiente e dos indivíduos para fornecer bases para outras análises 
mais detalhadas (Miguel, 2012). A presente pesquisa não utiliza métodos estatísticos, baseando-se nas opiniões e na experiência da equipe participante.

O procedimento técnico utilizado para o desenvolvimento dos trabalhos foi a pesquisa participativa. Segundo Prodanov e Freitas (2003), esse procedimento caracteriza-se pela realização conjunta do desafio de pesquisar e participar de forma constante e ele auxilia os envolvidos a resolverem os seus próprios incômodos por meio da pesquisa.

Como consequência da utilização do procedimento de pesquisa participativa, a construção das discussões foi adaptada ao contexto do estudo, de forma a garantir que o trabalho não se distanciasse da realidade do ambiente. Dessa forma, foram explanados parâmetros importantes destacados pela gestão de manutenção da empresa em estudo, de forma a justificar as mudanças realizadas no ambiente produtivo. Por isso, tornou-se importante conceituar e explicar as técnicas empregadas no setor de recuperação de componentes ferroviários de forma simplificada.

Para a realização dos estudos, optou-se primeiro pela caracterização e contextualização da empresa, bem como do ambiente de implantação das intervenções realizadas. Logo após, foi realizada a análise da situação anterior às intervenções e à coleta dos requisitos do projeto. Esse método foi desenvolvido internamente na organização e é constituído pelos seguintes tópicos: relato dos problemas considerados prejudiciais à unidade produtiva; análise do objetivo organizacional influenciado pelo problema; descrição dos indicadores que podem ser afetados caso o problema não seja solucionado; levantamento das hipóteses que caracterizam a influência negativa do problema; preenchimento da matriz de criticidade, responsável pela avaliação qualitativa do risco, por meio da soma de sua probabilidade e de sua gravidade e a criação de ações para solucionar os problemas, com o auxílio da equipe da gerência.

É importante ressaltar que a criticidade é analisada a partir das ponderações das opiniões individuais dos responsáveis pelo ambiente. Essas opiniões são analisadas em reuniões semanais, onde torna-se possível determinar a probabilidade de determinada situação acontecer e a gravidade dos impactos causados caso o problema não for resolvido. O resultado, aqui intitulado como criticidade do risco, demostra como devem ser as prioridades de resolução dos problemas.

Após o levantamento e entendimento dos requisitos, eles foram dispostos em uma EAP, com seus respectivos desdobramentos, de forma a organizar a apresentação das medidas executadas. Após a implantação destas medidas, os resultados foram descritos e analisados, sendo apresentadas todas as iniciativas que melhoraram as condições de trabalho no local. Além disso, foram propostas melhorias futuras para o ambiente estudado. Os resultados apresentados na pesquisa remetem às intervenções feitas no período de maio de 2018 até março de 2019. 


\section{Caracterização do caso}

Neste tópico são descritas as características da empresa, do setor e do processo onde foram realizadas as intervenções. Na sequência, são abordados aspectos importantes sobre as orientações organizacionais que guiaram as intervenções, assim como as demandas e estratégias da área.

\subsection{Caracterização e contextualização da empresa}

A história da MRS Logística inicia-se com o sancionamento da Lei de Concessões 9.987/95, a qual estabeleceu o processo de desestatização da malha ferroviária de 1.674 KM da região Sudeste, e foi responsável pela criação dos direitos e obrigações para as partes envolvidas no processo, bem como o modelo de concessões. A empresa foi, então, criada em 1996, em decorrência da privatização do sistema ferroviário nacional.

A malha ferroviária concedia à MRS é responsável pelo transporte de produtos distintos, como contêineres, produtos siderúrgicos, cimento, bauxita, coque e carvão, sendo os commodities, o maior volume de transporte. A MRS Logística tem suas operações focadas no transporte de carga na região Sudeste, a qual possui considerável influência no PIB brasileiro, dada a importância dos estados de Minas Gerais, Rio de Janeiro e São Paulo na produção nacional.

A empresa caracteriza-se como uma sociedade anônima, tendo o seu capital dividido em ações, distribuídas da seguinte forma: MBR (32,9\%), CSN (18,6\%), Congonhas Minérios (18,6\%), UPL (11,1\%), Vale (10,9\%), Gerdau (1,3\%) e um grupo pulverizado de pequenos investidores (6,5\%) (MRS Logística, 2014). A sociedade foi criada com o único intuito de desenvolver as operações da Rede Ferroviária Federal S.A (RFFSA) (Brasil, 1996). Suas operações são viabilizadas através de uma frota de aproximadamente 18 mil vagões e 800 locomotivas, o que representa $6 \%$ da estrutura férrea nacional.

A MRS Logística, nos últimos tempos, buscou uma nova cultura com iniciativas, focados na gestão de segurança, marcando uma nova fase de liderança, que visou aumentar o combate à imprudência nos trabalhos perigosos e reduzir os índices de acidentes, o que justifica a utilização de questões relacionadas à segurança como fator importante para a tomada de decisões e a satisfação dos seus colaboradores (Costa, M. 2016). Essa busca por uma cultura com foco em segurança é explicada, em parte, pela utilização do índice de acidentes pelo governo como um indicativo da qualidade do serviço oferecido pelas concessões (Lang, 2007).

\subsection{Análise do setor}

O setor em estudo está alocado dentro da Gerência Geral de Manutenção de Vagões da MRS Logística, que tem como objetivo buscar a maior confiabilidade dos vagões, de forma a cumprir o plano de uso desses ativos e atender às necessidades de demanda de transporte da MRS. O setor é 
denominado Gerência de Manutenção de Vagões-MG (GMVMG) e é responsável tanto pela manutenção de vagões, quanto por atividades que auxiliam na recuperação de seus componentes. 0 setor também é responsável por prestar atendimento aos acidentes ferroviários, sendo a Diretoria de Engenharia e Manutenção responsável pela determinação de suas metas e diretrizes.

\section{Figura 1}

\section{Subsistemas que Compõe um Vagão}

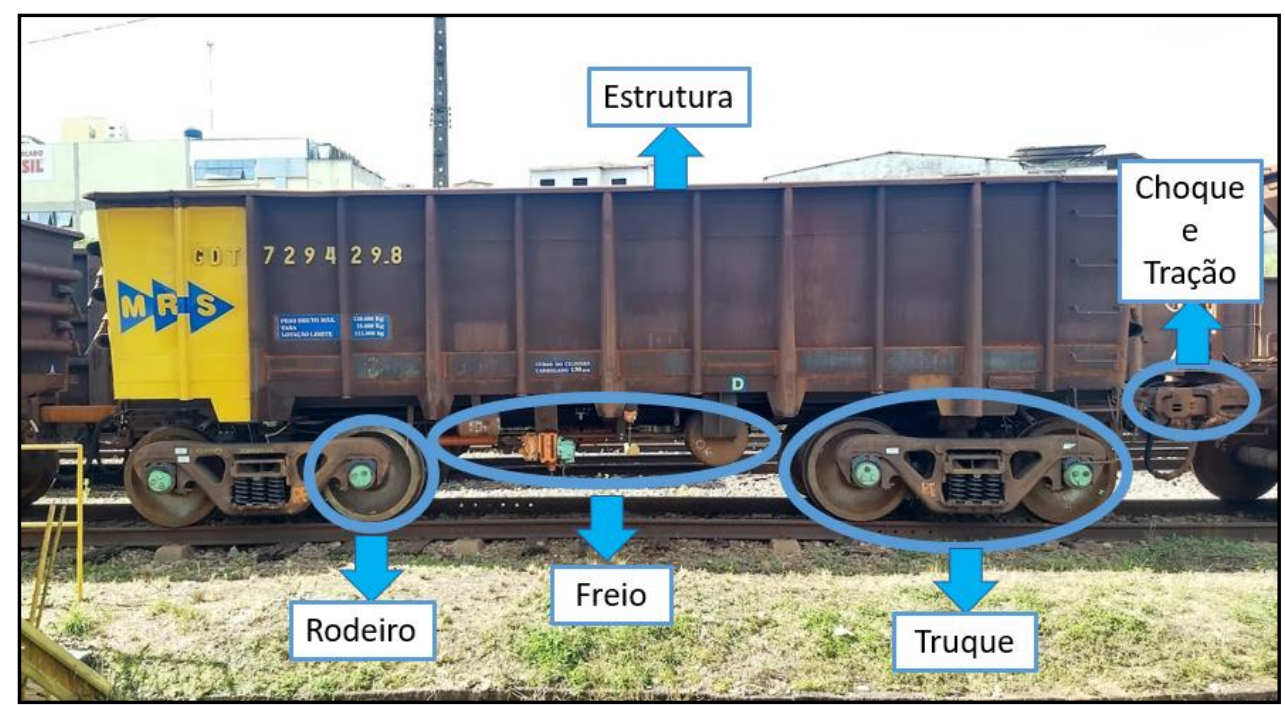

Fonte: Próprio autor.

Os vagões são divididos em cinco subsistemas para facilitar a organização do processo de manutenção da GMVMG: Estrutura, Choque e Tração, Rodeiro, Truque e Freio (Freitas, 2015). A Figura 1 apresenta as indicações destes subsistemas.

Os 203 funcionários que, na atualidade, compõem o efetivo da GMVMG trabalham para realizar manutenções principalmente nas frotas de vagões gôndola do tipo GDT e GDU. Estas frotas são responsáveis pelo transporte de produtos que podem ser expostos ao tempo, compreendendo a carga Heavy Haul e os contêineres.

Vale ressaltar que a GMVMG tem metas específicas, tanto para a segurança pessoal e ferroviária, quanto para questões ambientais, além de metas direcionadas à produtividade, relacionadas ao aproveitamento e performance da mão de obra. A GMVMG deve garantir que o serviço de manutenção prestado seja realizado com qualidade, para atender o seu cliente no tempo previsto e com aderência ao planejamento de custos. 
Figura 2

Vista Ilustrativa do Subsistema Truque

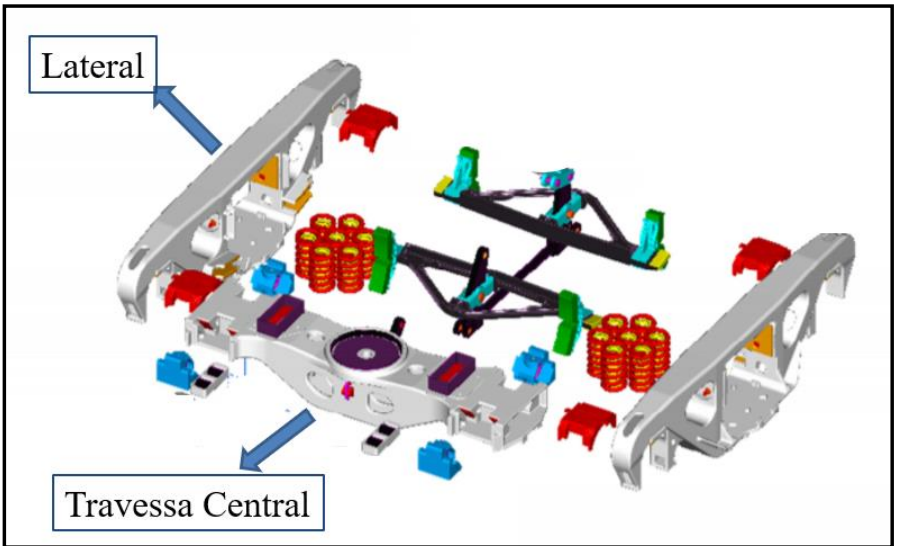

Fonte: Adaptado de Fundamentos de vagões MRS, 2015.

Para compreender a importância das condições adequadas do truque ferroviário (Figura 2), deve-se ressaltar o seu papel em garantir a fixação da estrutura do vagão, além de ser responsável pelo equilíbrio e a estabilidade do vagão na sua movimentação. Um ponto relevante é que, na interface entre a travessa central e as laterais, se encontram as molas e cunhas de fricção, responsáveis pela dinâmica do material rodante, destacadas nas cores vermelhas e azuis, respectivamente (Costa, F. 2016).

A recuperação de truques pode ser dividida, de forma simplificada, em três etapas: a desmontagem, realizada por dois mantenedores mecânicos; a soldagem, realizada por um mantenedor metalúrgico; e a montagem, realizada pelos mesmos dois mantenedores mecânicos responsáveis pela desmontagem. Para garantir uma melhor confiabilidade do componente, é realizada a recuperação parcial da travessa central no processo de soldagem, ocorrendo a troca das chapas de desgaste da cunha. Esse processo é realizado para garantir a estabilidade e a performance do vagão.

Para entender o processo do teste de partículas magnéticas, é necessário conhecer a função dos itens de vagões que são tratados por essa técnica. O truque é formado por eixo, rodas, mancal de rolamentos e adaptadores. O adaptador de pedestal (Figura 3) é responsável por transferir a carga dos truques para os rolamentos, proporcionando a frenagem dos trens sobre os trilhos. Este componente é fabricado em aço fundido ou forjado e pode ser observado em três dimensões distintas: 6,5" x 9"; 6,5" × 12"; e 7" × 12", e deve passar pelo teste de partículas, para garantir o seu perfeito estado físico (Freitas, 2015). 


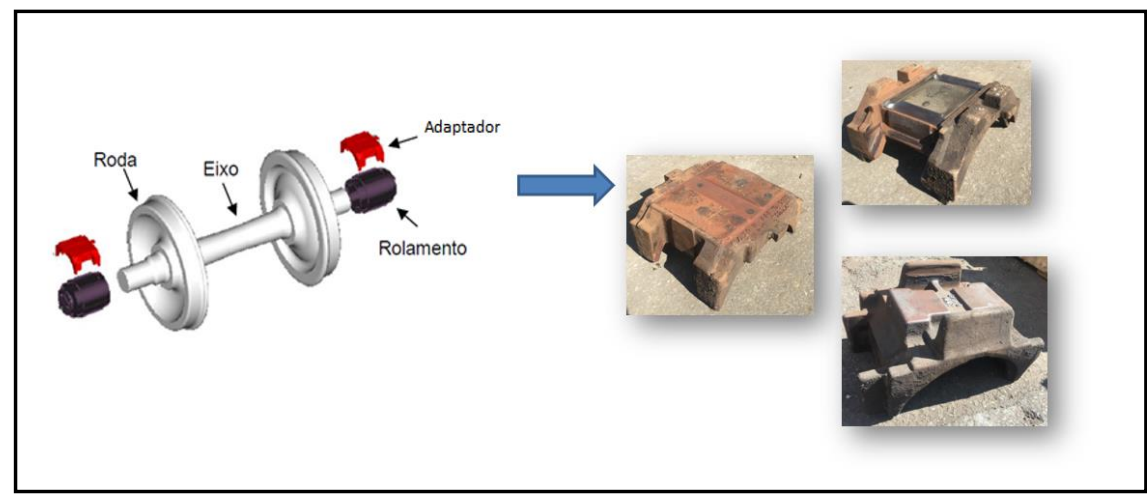

Fonte: Adaptado de Freitas, 2015.

O teste de partículas magnéticas também é realizado em itens que compõem o subsistema do vagão denominado choque e tração. O choque e tração compreendem um conjunto de itens confeccionados em aço fundido que é instalado nas extremidades dos vagões para acoplar outros vagões e/ou locomotivas. O item abordado deve resistir às forças de tração e compressão e aos impactos ocasionados pelas variações de velocidades na condução e manobra dos trens (Freitas, 2015). O pino e a mandíbula, apresentadas na Figura 4, são os únicos itens do subsistema de choque e tração, submetidos ao teste de partículas magnéticas na GMVMG, o qual busca garantir que os itens citados não sofram rompimento durante a movimentação dos vagões.

O teste de partículas magnéticas visa localizar descontinuidades superficiais em materiais ferromagnéticos. O teste possibilita a visualização de trincas e, consequentemente, a indicação de defeitos. Isso se dá com a utilização de um campo magnético em conjunto com partículas magnéticas amarelas, o que faz com que seja possível visualizar as trincas, que podem gerar rupturas durante o processo de movimentação (Franco, 2015).

O processo pode ser feito de maneira seca ou úmida com o auxílio de uma ferramenta, chamada Yoke Portátil, desenvolvida em ferro macio e composta por bobinas enroladas em torno de um núcleo em forma de U. Ressalta-se que também é executado um teste dimensional para garantir que as mandíbulas e os adaptadores de pedestal não sofreram grandes deformações durante a movimentação do trem. 
Figura 4

Imagem do Pino e da Mandíbula que passam pelo teste de partículas
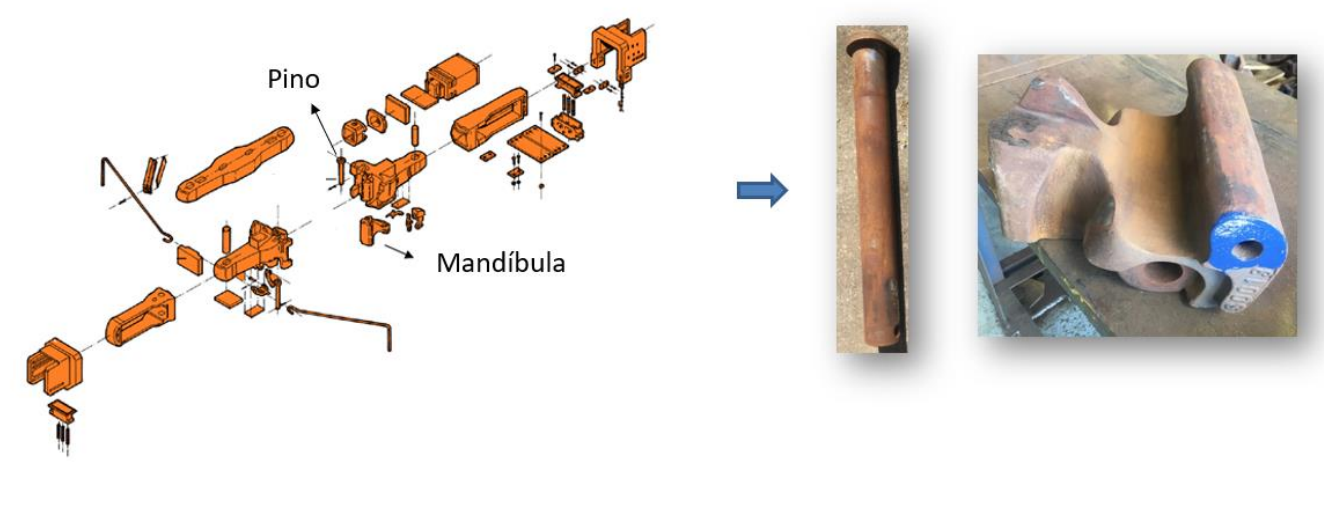

Fonte: Adaptado de Freitas, 2015.

\subsection{Problematização}

A área de recuperação de truques e testes de partícula pode ser considerada como uma fornecedora importante de recursos para a manutenção das atividades logísticas da MRS. O seu funcionamento adequado garante as boas condições dos vagões, reduzindo o índice de acidentes ferroviários, o que afeta diretamente a produção da organização.

O funcionamento da área foi autorizado entre o período de 2018 até 2021, podendo ser prorrogado de acordo com a necessidade de redução de custo e garantia da produção da manutenção. A implantação da área foi uma necessidade imediata, o que não permitiu um planejamento prévio de todos os requisitos do ambiente de trabalho. Isso gerou pontos de adaptação, os quais foram tratados neste estudo. Destarte, este estudo mostrou como foram levantadas e realizadas essas modificações, em plena operação da manutenção. Para isso, foi necessário a colaboração das equipes operacional e de gestão para implantar melhorias nas condições de trabalho e proporcionar um layout com recursos mais adequados.

\section{Resultados e discussões}

O desenvolvimento dos estudos para a definição e implantação do layout, bem como as intervenções realizadas no ambiente, são apresentados neste tópico. Foi descrito como era o ambiente de produção e foi analisada a necessidade de intervenções, além da discussão dos principais impactos e das sugestões de próximas intervenções. 


\subsection{Análise da situação anterior à intervenção}

Foi necessário um reconhecimento detalhado do ambiente. Essa representação, foi importante para que a equipe pudesse analisar onde a área está localizada e como a infraestrutura disponível era distribuída para outros setores que não têm ligação direta com a manutenção. Foi preciso considerar o acesso em cada ambiente vizinho para evitar problemas de deslocamento e outras interferências com setores mais complexos.

Por meio da construção do esboço, pôde-se compreender o funcionamento do ambiente, tornando possível verificar importantes iniciativas de mudanças no projeto. Dentre as oportunidades que foram destacadas, podem ser citadas a criação de mudanças, para facilitar o aprendizado do processo; e a organização, para evitar perdas de tempo na busca por recursos necessários à manutenção e à determinação de um espaço mais adequado. As oportunidades levantadas foram alinhadas com os mantenedores, a fim de considerar uma maior facilidade na realização da manutenção, com menores custos e maior segurança.

A visualização de todos os elementos serviu como base para a formulação dos requisitos necessários para a adaptação do layout, os quais foram listados e detalhados para melhor compreensão.

\subsection{Levantamento dos requisitos para o ambiente de trabalho}

\section{Quadro 1}

Requisitos que foram levantados

\begin{tabular}{|c|l|l|c|}
\hline Na & \multicolumn{1}{|c|}{ Requisito } & Indicadores de Impacto & Matriz de criticidade \\
\hline 1 & $\begin{array}{l}\text { Necessidade de ampliação do } \\
\text { espaço liberado para a } \\
\text { separação de ambientes por } \\
\text { produto trabalhado. }\end{array}$ & Produtividade/Segurança & Intolerável \\
\hline 2 & $\begin{array}{l}\text { Condições de armazenamento } \\
\text { adequadas. }\end{array}$ & Produtividade/Segurança & Moderado \\
\hline 3 & $\begin{array}{l}\text { Uso adequado de } \\
\text { equipamentos de proteção } \\
\text { individual, ferramentas e } \\
\text { instrumentos. }\end{array}$ & Produtividade/Custo/Segurança & Substancial \\
\hline 4 & $\begin{array}{l}\text { Melhoria das condições dos } \\
\text { recursos elétricos. }\end{array}$ & Produtividade/Segurança & Aceitável \\
\hline 5 & $\begin{array}{l}\text { Adequação do estoque de } \\
\text { ferramentas e recursos para } \\
\text { emergências. }\end{array}$ & Produtividade/Custo/Segurança & Substancial \\
\hline 6 & $\begin{array}{l}\text { Armazenamento dos } \\
\text { suprimentos em localização e } \\
\text { forma adequada. }\end{array}$ & Produtividade/Custo/Segurança & Substancial \\
\hline
\end{tabular}

Fonte: Elaborado pelo autor. 
Após o reconhecimento das necessidades de melhoria na instalação fabril, buscou-se, em conjunto com os mantenedores, identificar os requisitos desejados para um bom ambiente de trabalho (Quadro 1). Para tal finalidade, houve a necessidade de uma convivência próxima ao ambiente produtivo e a compreensão das dificuldades e desconfortos dos mantenedores. Esses requisitos foram analisados quanto ao seu impacto nos indicadores da Gerência de Manutenção de Vagões-MG, de forma a determinar o seu nível de criticidade.

Com a devida compreensão dos requisitos, foram levantadas ações que fizessem com que o ambiente produtivo se tornasse um espaço mais produtivo e seguro, além de auxiliar as devidas formas de utilização dos recursos. Abaixo, constam os desdobramentos de cada requisito, com a análise realizada junto ao mantenedor, além das ações criadas para cada abordagem.

- Requisito 1: Necessidade de ampliação do espaço liberado para a separação de ambientes por produto trabalhado.

Com o auxílio da equipe da Gerência de Manutenção de Vagões-MG, foi analisada a necessidade de determinação de um maior espaço produtivo. Esse foi classificado como intolerável pela matriz de criticidade, ao analisar o problema "Existem múltiplos processos que são realizados adequadamente?".

A necessidade de mais espaço para o ambiente produtivo se justifica, visto que a soma das áreas dos itens que são necessários para constituir o ambiente de produção é maior que a área disponibilizada. O cálculo realizado considerou apenas o espaço físico do mobiliário, então como também existe a necessidade de uma área de movimentação, ressalta-se que o ambiente necessita de um espaço maior do que a área coberta apontada. Uma vez que a empresa possui políticas orientadas para a segurança de seus funcionários, o espaço deve refletir essa preocupação, prezando pelo trabalho em áreas com proteção contra intempéries. Além disso, a análise demonstrou problemas quanto à movimentação do fluxo produtivo, bem como a falta de espaço necessário para a movimentação segura de pessoas e das empilhadeiras, o que justifica a classificação do risco como intolerável.

Ao longo do processo de análise, foi possível observar que a separação dos meios produtivos é um ponto importante para a eficiência do layout. Isso se dá em função da criação de espaços separados proporcionar uma melhor movimentação dos funcionários, de forma a garantir um ambiente com menos barreiras produtivas e desvios de segurança. 
Tabela 1

Lista de itens necessários para o ambiente produtivo

\begin{tabular}{|c|c|c|c|c|}
\hline $\mathrm{n} \mathbf{a}$ & ITENS & LARGURA (m) & COMPRIMENTO (m) & ÁREA TOTAL $\left(\mathrm{m}^{2}\right)$ \\
\hline 1 & Computador desktop & 1,5 & 1 & 1,5 \\
\hline 2 & Armário de ferramentas & 1,7 & 1,7 & 2,89 \\
\hline 3 & Mesa e cadeira & 1,5 & 1,7 & 2,55 \\
\hline 4 & Equipamento de oxicorte & 3 & 1,7 & 5,1 \\
\hline 5 & Área de Biombos & 1,7 & 1,7 & 2,89 \\
\hline 6 & Maquina de Solda Mig & 1 & 0,6 & 0,6 \\
\hline 7 & Área de Palets & 1,7 & 1,7 & 2,89 \\
\hline 8 & Mesa de talhas & 2,4 & 3,7 & 8,88 \\
\hline 9 & Mesa de recuperação de truques & 1,6 & 1,8 & 2,88 \\
\hline 10 & Kanban & 3 & 1,7 & 5,1 \\
\hline 11 & Mesa de testes de partículas & 5,7 & 4 & 22,8 \\
\hline 12 & Armário de produtos quimicos & 1,5 & 1,7 & 2,55 \\
\hline 13 & Kit de Limpeza & 1 & 1,7 & 1,7 \\
\hline 14 & Caixa de primeiros socorros & 1 & 1,7 & 1,7 \\
\hline 15 & Armário de EPI's & 1,7 & 1,7 & 2,89 \\
\hline 16 & Mapa de Risco & 1 & 1 & 1 \\
\hline 17 & $\begin{array}{l}\text { Mesa temporária para molas e } \\
\text { cunhas }\end{array}$ & 1,5 & 1,7 & 2,55 \\
\hline 18 & Extintor de incêndio & 1 & 1 & 1 \\
\hline 19 & Sucata & 1,8 & 1 & 1,8 \\
\hline \multicolumn{4}{|c|}{ Área necessária para todos os itens } & 73,27 \\
\hline \multicolumn{4}{|c|}{ Área Interna inicial } & 57 \\
\hline \multicolumn{4}{|c|}{ Área faltante para condicionar todos os itens necessários para o processo } & 16,27 \\
\hline
\end{tabular}

Fonte: Dados de pesquisa.

De acordo com as características de cada item produzido, foi possível compreender a classificação do arranjo físico, suas vantagens e suas limitações (Quadro 2). Essa classificação auxiliou nas buscas por oportunidades de melhoria no espaço analisado, e permitiu identificar a necessidade de ambientes separados para cada tipo de produto trabalhado. Observou-se, então, que não é recomendável utilizar ambientes onde não seja possível visualizar o correto fluxo de processo. Um ambiente sem a devida separação de processos diferentes proporciona fluxos não padronizados, que podem gerar perdas na qualidade das entregas, além de propiciar barreiras produtivas e oportunidades para gerar um acidente pessoal.

A execução do Requisito 1, referente à ampliação do espaço liberado para as atividades, teve início com a ocupação de uma área do galpão que estava em posse de outra gerência. Assim, foi possível a separação dos dois processos produtivos. Posteriormente foram realizadas as medições e a mudança do mobiliário, de forma a satisfazer tanto a necessidade dos mantenedores, quanto da equipe de 
gestão. Devido à revitalização do piso, foi necessário realizar uma parada na produção, e ocasionou também uma área segura para movimentação da Monovia, que já estava disponível para a utilização no ambiente produtivo.

\section{Quadro 2}

\section{Classificação dos Layouts para cada produto}

\begin{tabular}{|c|c|c|}
\hline Característica & Item 1 & Item 2 \\
\hline Produto & Truque & Pino, mandíbula e adaptadores. \\
\hline Processo & Recuperação Parcial & Teste de partículas \\
\hline $\begin{array}{c}\text { Classificação do } \\
\text { arranjo físico }\end{array}$ & Posicional & Produto \\
\hline Vantagem & $\begin{array}{l}\text { *Reduzida movimentação do material. } \\
\text { *O trabalhador consegue conhecer o trabalho } \\
\text { como um todo. } \\
\text { *Alta flexibilidade da produção, pois pode } \\
\text { acomodar mudanças no projeto do produto e no } \\
\text { volume de produção. }\end{array}$ & $\begin{array}{l}\text { *Fluxo suave, simples e direto. } \\
\text { *Baixo estoque em processo. } \\
\text { *Menor tempo de produção unitário. } \\
\text { *Controle de produção simples. } \\
\text { *Menor movimentação de material } \\
\text { durante o processo. } \\
\text { *Requer menor habilidade do pessoal. } \\
\text { *Podem ser usados equipamentos } \\
\text { especializados. }\end{array}$ \\
\hline Limitação & $\begin{array}{l}\text { *Maior movimentação de mão de obra e } \\
\text { equipamentos/ferramentas. } \\
\text { *Pode resultar em aumento de compras de } \\
\text { equipamentos/ferramentas. } \\
\text { *Pode necessitar de grandes espaços e maior } \\
\text { estoque em processo. } \\
\text { *Programação da produção mais complexa. }\end{array}$ & $\begin{array}{l}\text { *Parada de máquina para a linha. } \\
\text { *Mudança do produto por causa } \\
\text { obsolescência no arranjo físico. } \\
\text { *Trabalho pode ser repetitivo. } \\
\text { *Requer supervisão geral. }\end{array}$ \\
\hline
\end{tabular}

Fonte: Adaptado Argoud,2007.

- Requisito 2: Condições de armazenamento e separação dos itens pelos processos.

Um dos pontos evidenciados pelos colaboradores da gerência foi garantir as devidas condições de armazenamento dos pinos, mandíbulas e adaptadores que passam pelos testes de partículas, criando uma adaptação que facilite alcançar o tempo de manutenção padrão. Esse requisito foi analisado por meio do problema "Como devem ser as devidas condições de armazenamento temporário dos truques, pinos e mandíbulas, que irão passar pelos processos?".

A devida organização e as boas condições para os suprimentos destinados ao processo de teste de partícula foram pontos considerados de melhorias, pois condições inadequadas geram um ambiente perigoso no que tange à integridade física do colaborador. A matriz de criticidade para esse problema mostra um risco moderado, o que ressalta a importância da execução das ações propostas. 
Para alcançar o Requisito 2, referente ao armazenamento e à separação dos itens, realizou-se a delimitação de espaços específicos para cada componente. Além disso, determinou-se o volume máximo de itens que poderiam ocupar esses espaços, bem como o fluxo de entrada e saída dos processos produtivos. Dentre as atividades realizadas neste pacote de trabalho, a determinação do volume máximo foi o maior desafio, pois ele varia conforme o plano de manutenção de vagões, exigindo o aprofundamento no planejamento da produção do setor abordado.

- Requisito 3: Uso adequado de equipamentos de proteção individual, ferramentas e instrumentos.

Os equipamentos de proteção individual são disponibilizados pela empresa para reduzir o risco de acidentes pessoais. O colaborador deve estar ciente de que, a eficiência de um equipamento de proteção Individual (EPI), está ligada diretamente à sua percepção e à análise de risco realizada (Neves, 2011). Condições de armazenamento inadequadas, assim como as devidas condições dos instrumentos e ferramentas, podem afetar negativamente o planejamento de custos, a segurança e a produtividade. O requisito em questão, relacionado à análise do problema "Como devem ser guardadas as ferramentas, instrumentos e EPIs para realizar a manutenção?", apresenta um risco substancial na matriz de criticidade, o que ressaltar a importância da execução das ações para a tratativa adequada deste problema.

A implantação do Requisito 3, relativo ao uso adequado de equipamentos de proteção individual, ferramentas e instrumentos, foi realizada com maior facilidade, uma vez que compreende práticas comuns dentro do setor de manutenção. Para tal, armários antigos de outros setores que não eram mais utilizados, foram reformados para a armazenagem de EPIs e de ferramentas. Foram criadas prateleiras, por meio do aproveitamento de chapas utilizadas na estrutura do vagão, e, também, utilizadas tintas provenientes do teste de partículas. Posteriormente, os armários foram devidamente identificados.

- Requisito 4: Melhoria das condições dos recursos elétricos.

A otimização das condições elétricas do galpão foi uma necessidade relatada pelos envolvidos no processo de produção, sendo verificadas ações necessárias para melhoria das instalações. Problemas observados, como a falta de identificação das tomadas, cabos em más condições e a necessidade de dedetização, foram vistos como oportunidades de mudança, conforme é apresentado no Quadro 8. Dessa forma, o problema "Como devem estar às condições da área elétrica do galpão?" foi analisado, sendo classificado como risco aceitável na matriz de criticidade, por apresentar um baixo potencial de gravidade. 
Embora o risco tenha sido considerado como Trivial, foram propostas ações para a tratativa deste requisito, uma vez que o foco foi a segurança e o conforto dos trabalhadores. O Requisito 4, que trata das condições elétricas do galpão, demandou um tempo maior, dada a necessidade de cotação de itens como os cabos elétricos. O processo de orçamento e planejamento de compra foi devidamente respeitado gerando um prazo maior para seu atendimento.

- Requisito 5: Adequação do estoque de ferramentas e recursos para emergências.

Com a mudança da área de testes de partículas magnéticas e, consequentemente, o deslocamento de pessoas e componentes ferroviários, foram evidenciadas necessidades de melhoria nas condições de condicionamento dos recursos utilizados no atendimento a emergências de acidentes ferroviários. A equipe operacional que trabalha no ambiente, assim como os responsáveis por gerenciar estes recursos, identificaram a necessidade de organização das condições do espaço, dada a movimentação de pessoal na área. Neste requisito, pode-se observar, detalhadamente, os fatores levados em consideração para a intervenção, além de demostrar, por meio da matriz de criticidade, um risco substancial quanto ao gerenciamento dos recursos.

O Requisito 5, referente ao estoque de ferramentas e recursos para emergências, foi realizado por meio da redução do número de itens dentro do local. Iniciou-se um processo de identificação destes itens e, posteriormente, a criação de um padrão de monitoramento dos mesmos. Essa iniciativa foi tratada de maneira delicada e criteriosa, pois muitos dos itens disponíveis foram fabricados pelos próprios mantenedores, os quais mantinham um sentimento de posse por eles.

- Requisito 6: Armazenamento dos suprimentos em local e forma adequada.

O último requisito levantado diz respeito à definição da localização mais adequada para o armazenamento dos suprimentos necessários para as atividades de manutenção, sendo eles os "Parafusos Torx Cabeça Chata 1", as "Porcas de Fixação do Transon", as chapas para a realização do processo de soldagem, as cunhas e as molas. Foi verificado que, a disponibilidade de suprimentos em estoque deve ser monitorada ao longo da execução das atividades da área, o que proporciona um melhor planejamento da reposição dos itens. O Requisito 6 apresentou com mais detalhes a necessidade de intervenção, além de mostrar a avaliação do problema pela matriz de criticidade. A análise indica um risco substancial, fazendo com que o requisito seja considerado como muito relevante para o grupo de trabalho.

Os trabalhos que foram realizados para alcançar o Requisito 6, armazenamento dos suprimentos, foram considerados mais difíceis de serem executados. Isso se deu devido à necessidade de reforma de mobiliário antes utilizado para a produção. Um ambiente visivelmente mais agradável foi 
conquistado a partir da transformação das caixas de locação de painéis eletroeletrônicos em armários e das adequações das mesas para condicionamento de molas e cunhas. É importante ressaltar que a reforma/adaptação das mesas trouxe consigo um trabalho de conscientização sobre o número máximo de itens que uma mesa pode suportar.

\subsection{Implantação do layout}

A EAP criada para o projeto, disponível na Figura 5, representa o desmembramento dos requisitos levantados em atividades executadas no processo de intervenção e posteriormente a Figura 6 mostra como foi visível a transformação do local, que melhorou o acesso aos itens, suprimentos e materiais. Essas atividades representam as abordagens práticas mais relevantes que foram utilizadas para se alcançar cada requisito. Para que o grupo de trabalho pudesse visualizar o espaço disponível e a distribuição dos componentes, para a recuperação de truques e realização do teste de partículas, foi construído um desenho esquemático com a indicação de distâncias aproximadas e distribuição entre os itens do processo (Figura 6), antes e depois da iniciativa de melhoria, para que seja reconhecido a melhoria. 
Figura 5

EAP Desenvolvida por Pacotes de Trabalho Para Cada Requisito

GALPÃO DE MANUTENÇÃo PARCIAL DE TRUQUES

E REALIZAÇÃO DE TESTES DE PARTíCULAS

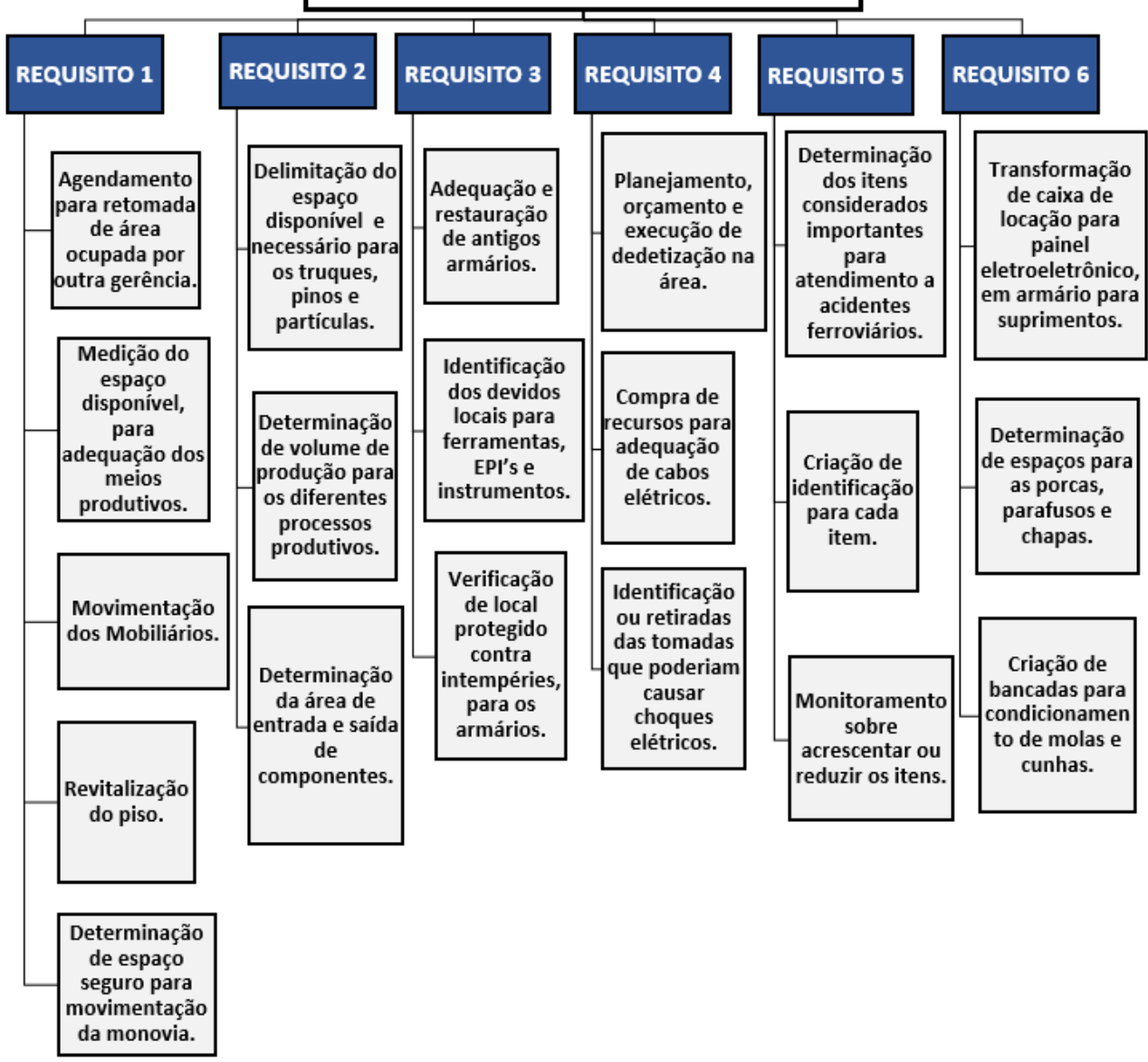

Fonte: Elaborada pelo autor.

A partir da implantação dos requisitos levantados, pode-se observar que o indicador de maior influência para a realização das adaptações no layout foi o de segurança. Esse indicador está relacionado a todas as ações para melhoria do ambiente produtivo.

Este trabalho possibilitou uma redução de barreiras para a produção, quando comparado a situação anterior. A organização dos componentes que passaram pelos processos proporcionou ganhos tanto para o próprio setor quanto para os outros que dependem dele. Entende-se que a redução de itens expostos ao tempo auxiliará quanto à durabilidade dos mesmos e, consequentemente, resultará em gastos menores de manutenção, além de melhorar a segurança em seu manuseio. 


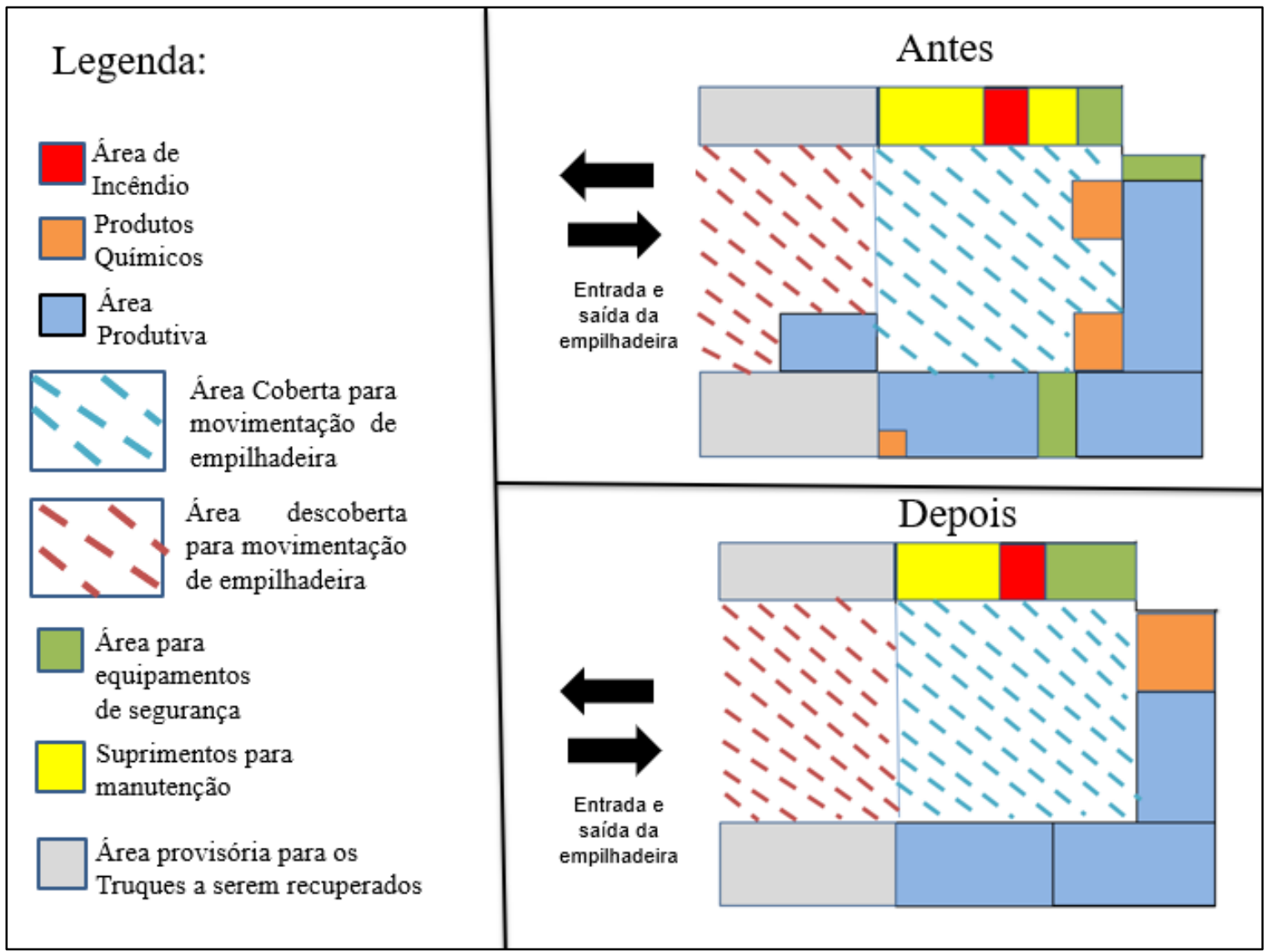

Fonte: Elaborada pelo autor.

\section{Considerações finais}

Esta pesquisa descreve o processo de aplicação de melhorias no layout da oficina de recuperação de truques da MRS Logística, com a utilização de argumentos baseados nos indicadores da empresa e nos requisitos de um projeto ideal de unidade produtiva. A situação existente da fábrica, antes da implantação das mudanças, foi analisada em conjunto com a equipe da Gerência de Manutenção de Vagões-MG. Posteriormente determinou-se a execução de ações, de forma a melhorar o ambiente de trabalho.

A pesquisa participativa se mostrou uma técnica essencial para retratar a importância do alinhamento da equipe com os objetivos da empresa, principalmente quanto às oportunidades de eliminação de riscos à segurança pessoal e operacional. Esta pesquisa forneceu uma base para a criação de melhorias no ambiente físico que mitigasse o problema de produtividade que prejudicava o planejamento de custos da unidade produtiva. As ações para garantir o planejamento dos custos se basearam em iniciativas que aumentaram a durabilidade dos maquinários, das ferramentas e dos equipamentos de proteção individual. 
Após a implantação das alterações, uma análise econômica sobre os benefícios da implantação da área em estudo foi realizada com a finalidade de verificar os impactos em custos. O setor de recuperação abordado trouxe uma economia de $\mathrm{R} \$ 2.408 .313,00$ no período de junho a dezembro do ano de 2018, o que demonstra a importância de investir em melhorias neste ambiente operacional.

O referencial teórico apresentou elementos relacionados ao arranjo físico e a projetos aplicados ao ambiente de trabalho, os quais aumentaram o nível de percepção sobre a importância das condições físicas para os colaboradores e para a empresa. Ao mesmo tempo, a construção do referencial teórico auxiliou no diálogo e na reflexão das iniciativas de mudanças. A metodologia utilizada, por sua vez, permitiu uma maior proximidade da gestão com o "chão de fábrica", e, consequentemente, a identificação de fatores considerados importantes para a diretoria da empresa.

Como limitação do estudo, ressalta-se a impossibilidade de modificar todos os itens necessários para alcançar uma unidade produtiva ideal. Isso se deve ao fato de o ambiente ser dinâmico e estar sempre em alteração para melhor atender à interação homem-ambiente, de forma a criar benefícios para os colaboradores e para a organização.

Como trabalho futuro, recomenda-se uma análise da possível utilização de espaços que hoje são cedidos para outras gerências. Um aumento da diversidade produtiva e um planejamento considerando todo o galpão podem ser alternativas para evitar possíveis paradas indesejadas na produção e riscos para a segurança, tanto pessoal quanto ferroviária. Outra sugestão para evitar um número elevado de paradas na produção, é a construção de uma metodologia com procedimentos que orientem novos projetos de unidades produtivas dentro da MRS Logística. A empresa já detém a prática de indicadores que avaliam a confiabilidade do processo, a segurança operacional/ambiental e o comportamento dos envolvidos frente a suas obrigações produtivas. Assim, nota-se a oportunidade de analisar esses indicadores para levantar parâmetros que auxiliem a modificação e construção de unidades fabris.

\section{Referências}

Albuquerque, S. (2018). A influência do Espaço construído no ambiente de trabalho/estudo. 85 f. TCC (Graduação) - Curso de Engenharia de Produção, IFMG-Campus Congonhas, 2018.

Andreto, L (2005). Influência do espaço construído na produtividade:Avaliação baseada na ergonomia do ambiente construído e na psicologia dos espaços de trabalho. Tese de Doutorado. Dissertação. PPGEP-UFPE, Recife.

Argoud, A. (2007). Procedimento para projeto de arranjo físico modular em manufatura através de algoritmo genético de agrupamento. Tese de Doutorado. Universidade de São Paulo. 
Baio, C., Falce, D., Rodrigues, M., Ludwig, V. (2016). Gerenciamento de Projetos: Diretrizes MRS. Juiz de Fora: Diretoria de Finanças e Desenvolvimento.

Bem, A. (2013). Análise do processo produtivo e proposta de melhorias no arranjo físico e no processo produtivo de uma indústria de mosaicos: um estudo de caso. Trabalho de Conclusão de Curso. Universidade Tecnológica Federal do Paraná.

Brasil. Ministérios dos Transportes. Contrato de Concessão Que Entre Si Celebram A União, Por Intermédio Entre O Ministério dos Transportes, e A Empresa Mrs Logística S. A.,Para Exploração e Desenvolvimento do Serviço Publico de Transporte Ferroviário de Carga na Malha Sudeste. no 37115342/0001-67. Diário Oficial da União. Brasília, Disponível em: https://www.mrs.com.br/wp-content/uploads/2014/07/Contrato-de-Concess\%C3\%A3o-MRSLog\%C3\%ADstica.pdf. Acesso em: 11 maio 2019.

Brasília. (2015).DNIT. Histórico Ferroviário. Disponível em: https://189.9.128.64/ferrovias/historico/historico\#wrapper. Acesso em: 21 jun. 2018.

Costa, F.(2016).Estudo da resposta dinâmica de truques ferroviários através de instrumentação de trilho e comparação com resultados de simulação dinâmica de vagões. Trabalho de Conclusão de Curso. Universidade Federal de Juiz de Fora.

Costa, M., Silva, R., Ferreira, M., Ramos Filho., A. (2017). Mudança de Cultura Organizacional TopDown: um estudo de caso. Revista de Administração da UNIFATEA, v. 13, n. 13.

Cruz, F. ( 2013) Scrum e PMBOK unidos no Gerenciamento de Projetos. Brasport.

Cubas, K., Figueiredo, T. (2015). H (app) Y:Gestão criativa da felicidade uma ferramenta para gerenciar o capital psicológico nas organizações. TCC(Especialização), Universidade Federal do Rio de Janeiro.

Favaretto, P., Kurek, J., Gomes, A. Caibre, D., Pandolfo, A. (2011). Projeto de Layout Industrial para uma Empresa do Ramo Meta-Mecânico com Base nos Princípios da Produção Enxuta. Revista Ciências Exatas e Naturais, v. 13, n. 1.

Franco, F. (2015).Partículas magnéticas. UNICAMP. Campinas: Slides. 42 slides, color.

Freitas,N. (2015) FUNDAMENTOS DE VAGÕES MRS. Juiz de Fora: s.n., (Apostila para Treinamento e desenvolvimento de funcionários da MRS Logística.).

Gama,P., Jacubavicius,C., Formigonl,A.(2015). Proposta de controle de escopo por meio da estrutura analítica do projeto (eap): estudo de caso. Sadsj -south American Development Societyjournal, São Paulo, v. 1, n. 1.

Gil, A. (2002). Como elaborar projetos de pesquisa. 4. ed. - São Paulo: Atlas.

Highsmith, J. (2004). Agile project management:Creating innovative products. Redwood City.

Kardec, A., Nascif,J.(2001). Manutenção-função estratégica.Qualitymark Editora Ltda.

Lang, A. (2007). As ferrovias no Brasil e avaliação econômica de projetos: uma aplicação em projetos ferroviários. Dissertação (Mestrado em transportes), Universidade de Brasília, Brasília. 
Machline, C. (1990) Manual de Administração da Produção. 9ạ ed. Rio de Janeiro: Editora Fundação Getúlio Vargas.

Masculo, F., Vidal, M. (2011). Ergonomia: trabalho adequado e eficiente. Elsevier Brasil.

Méxas, M. P., Correa, M. P. Q., de Castro, J. F. T., Drumond, G. M., \& Costa, H. G. (2019). É possível uma metodologia de gerenciamento de projetos mais leve e menos burocrática?. Revista GEPROS, 14(1), 300.

Miguel, P.(2012). Metodologia de pesquisa em engenharia de produção e gestão de operações. Elsevier.

MRS Logística. Quem Somos. (2014). Disponível em: https://www.mrs.com.br/empresa/quem-somos/. Acesso em: 11 maio 2019.

Neumann, C., Fogliatto, F.(2013) Sistemática para avaliação e melhoria da flexibilidade de layout em ambientes dinâmicos. Gestão e Produção, v. 20, n. 2, p. 235-254.

Neves, H. C. C., Souza, A. C. S., Medeiros, M., Munari, D. B., Ribeiro, L. C. M., \& Tipple, A. F. V. (2011). Segurança dos trabalhadores de enfermagem e fatores determinantes para adesão aos equipamentos de proteção individual. Rev Latino-Am. Enfermagem, 19(2), 354-361.

Pache, R., Silva, V. B., dos Santos, L. A., Garlet, E., \& Godoy, L. P. (2015). Princípios da manufatura enxuta como proposta para arranjo físico na indústria de transformação de termoplásticos. Engevista, 17(4), 507-524.

PMI. (2013). Um guia do conhecimento em gerenciamento de projetos (Guia PMBOK ${ }^{\circledR}$ ). Project Management Institute, Quinta Edição.

Prodanov, C., Freitas, E. (2003). Metodologia do trabalho científico: Métodos e Técnicas da Pesquisa e do Trabalho Acadêmico. Novo Hamburgo: Feevale.

Rodrigues, M. L., Malheiros, T. F., Fernandes, V., \& Dagostin Darós, T. (2012). A percepção ambiental como instrumento de apoio na gestão e na formulação de políticas públicas ambientais. Saúde e sociedade, 21, 96-110.

Salles JR, C. A., Soler, A. M., Valle, J. D., \& Rabechini Jr, R. (2006). Gerenciamento de riscos em projetos. Rio de Janeiro: FGV.

Slack, N., Chambers, S., Johnston, R. (2009). Administração da Produção. Tradução: Henrique Luiz Corrêa. 3ạ ed. São Paulo: Atlas.

Sotille, M. (2015). Gerenciamento do escopo em projetos. Editora FGV.

Tortorella, G., Fogliatto, F. (2008). Planejamento sistemático de layout com apoio de análise de decisão multicritério. Produção, v. 18, n. 3, p. 609-624.

Valle, A. (2015) Fundamentos do gerenciamento de projetos. Rio de Janeiro. Editora FGV.

Zanella, L. (2006). Metodologia da pesquisa. SEAD/UFSC. 